\title{
White-to-brown transdifferentiation of omental adipocytes in patients affected by pheochromocytoma
}

\author{
Andrea Frontini a , Alessandra Vitali a , Jessica Perugini a , Incoronata Murano ${ }^{a}$, Chiara Romiti a \\ Daniel Ricquier ${ }^{c}$, Mario Guerrieri ${ }^{a}$, Saverio Cinti ${ }^{\mathrm{a}, \mathrm{b}, *}$ \\ a Department of Experimental and Clinical Medicine, Center for the Study of Obesity-United Hospitals University of Ancona (Politecnica delle Marche), 60126 Ancona, Italy \\ b The Adipose Organ Lab IRCSS San Raffaele Pisana, 00163 Rome, Italy \\ c Université Paris Descartes, CNRS and INSERM Cochin Institute, Paris, France
}

\section{A R T I C L E I N F O}

\section{Article history:}

Received 8 December 2012

Received in revised form 7 February 2013

Accepted 9 February 2013

Available online 20 February 2013

\section{Keywords:}

Human

Pheochromocytoma

White adipose tissue

Brown adipose tissue

Browning

Morphology

\begin{abstract}
A B S T R A C T
In all mammals, white adipose tissue (WAT) and brown adipose tissue (BAT) are found together in several fat depots, forming a multi-depot organ. Adrenergic stimulation induces an increase in BAT usually referred to as "browning". This phenomenon is important because of its potential use in curbing obesity and related disorders; thus, understanding its cellular mechanisms in humans may be useful for the development of new therapeutic strategies. Data in rodents have supported the direct transformation of white into brown adipocytes. Biopsies of pure white omental fat were collected from 12 patients affected by the catecholamine-secreting tumor pheochromocytoma (pheo-patients) and compared with biopsies from controls. Half of the omental fat samples from pheo-patients contained uncoupling protein 1 (UCP1)-immunoreactive-(ir) multilocular cells that were often arranged in a BAT-like pattern endowed with noradrenergic fibers and dense capillary network. Many UCP1-ir adipocytes showed the characteristic morphology of paucilocular cells, which we have been described as cytological marker of transdifferentiation. Electron microscopy showed increased mitochondrial density in multi- and paucilocular cells and disclosed the presence of perivascular brown adipocyte precursors. Brown fat genes, such as UCP1, PR domain containing 16 (PRDM16) and $\beta 3$-adrenoreceptor, were highly expressed in the omentum of pheo-patients and in those cases without visible morphologic re-arrangement. Of note, the brown determinant PRDM16 was detected by immunohistochemistry only in nuclei of multi- and paucilocular adipocytes. Quantitative electron microscopy and immunohistochemistry for Ki67 suggest an unlikely contribution of proliferative events to the phenomenon. The data support the idea that, in adult humans, white adipocytes of pure white fat that are subjected to adrenergic stimulation are able to undergo a process of direct transformation into brown adipocytes. This article is part of a Special Issue entitled Brown and White Fat: From Signaling to Disease.
\end{abstract}

(C) 2013 Elsevier B.V. All rights reserved.

\section{Introduction}

In small mammals and to some extent also in humans, white adipose tissue (WAT) and brown adipose tissue (BAT) are found together in several fat depots located in subcutaneous and visceral areas. These can be regarded as one multi-depot organ with distinct morphology and specific functions, and all of the depots exhibit extremely plastic properties [1].

The two main types of cell forming the adipose organ are white and brown adipocytes, which fulfill the opposing functions of storing lipids for survival and consuming lipids to produce heat, respectively.

\footnotetext{
This article is part of a Special Issue entitled Brown and White Fat: From Signaling to Disease.

* Corresponding author at: School of Medicine, University of Ancona (Politecnica delle Marche) Via Tronto 10/A, 60020 Ancona, Italy. Tel.: + 390712206088.

E-mail address: cinti@univpm.it (S. Cinti).
}

Thermogenesis in BAT is mediated by a brown fat-specific mitochondrial protein, uncoupling protein 1 (UCP1), which plays an important role in the control of energy homeostasis. Indeed, the loss of UCP1 causes cold-intolerance [2] and obesity at thermoneutrality in mice [3]. The transgenic expression of UCP1 in WAT has been shown to combat obesity [4], whereas BAT removal or inactivation has been shown to cause obesity and related disorders $[5,6]$. Cold- and dietinduced thermogenesis are dependent on the ß-adrenergically mediated activation of lipolysis and the subsequent degradation of fatty acids via UCP1 that dissipates large amounts of chemical energy [7].

Recent studies using non-invasive imaging technologies, such as 18fluorolabeled 2-deoxy-glucose positron emission tomography (18FDG-PET), have clearly demonstrated that adult humans have significant amounts of active BAT in the area at the base of the neck and cold exposure has revealed that this tissue can be activated [8-12]. In a case series of adult humans, a histological study demonstrated the presence of true brown adipocytes in the same anatomical area and 
identified brown fat precursors [13]. Furthermore, the glucose uptake capacity in BAT correlates inversely with adiposity, indicating that variation in the amount and/or thermogenic activity of BAT may contribute to the propensity for weight gain in humans [14].

The mechanisms by which WAT acquires BAT-like properties are generally referred as "browning" and have been proven to be of great importance in protecting against diet-induced obesity and metabolic diseases $[15,16]$. Browning occurs especially in the subcutaneous depots of mice that over-express PR domain containing 16 (PRDM16) [17] which is the key transcriptional regulator of the cellular lineage that gives rise to the classic brown adipose depots in mice [18].

In addition, UCP1-immunoreactive (ir), brown fat-like cells can emerge in predominantly "white" depots upon prolonged cold exposure or 33 -adrenoreceptor (ADRB3) activation [19-22]. These brownlike fat cells, which are not derived from a Myf5 ${ }^{+}$lineage, are designated as brown-in-white (brite) cells [23], beige cells [24,25] or simply brown adipocytes, mainly because they have anatomy and physiology corresponding to that of other brown adipocytes found in specific areas of the adipose organ considered as the "classic" brown depot [26,27].

The propensity to accumulate brown adipocytes differs in individual WAT depots of rodents and seems to be dependent on different innervations of the depot [27] or different cell subtype compositions [28]. A large accumulation of brown adipocytes in the adipose organ during cold exposure can be found most readily in the subcutaneous inguinal adipose tissue but is rarely observed in epididymal/perigonadal adipose tissue $[17,27,29]$. We have recently described UCP1-ir paucilocular as a cell marker of the intermediate steps in the process of white-to-brown adipocyte transdifferentiation in mice subjected to adrenergic stimulation [22].

Based on classic [30] and more recent studies [31], the presence of active BAT in patients affected by pheochromocytoma (pheo-patients), which is a neuroendocrine tumor that intermittently secretes excessive amounts of catecholamines, is known to be enhanced. It has also been documented by FDG-PET that patients with this type of tumor showed higher levels of active BAT in several locations of the body; this situation reverted to normal after tumor resection $[32,33]$.

Because browning the human adipose organ may be a strategy to combat obesity and related disorders [34], it is important to investigate whether human white adipocytes can be converted into brown adipocytes and to determine the cell processes involved. Visceral fat deposits, especially mesenteric and omental fat, are generally considered "pure" white fat depots with little propensity to acquire a brown phenotype, even in rodents $[27,29]$. Thus, we selected these pure white depots in patients suffering from pheochromocytomas to investigate whether white-to-brown transdifferentiation can occur in this unique model of adrenergic hyper-stimulated human fat. In half of the samples analyzed, we observed all steps of the striking morphological changes in a typical transformation of WAT into BAT, including the presence of paucilocular adipocytes, an insignificant increase of adipocyte precursors and the re-organization of vascular and nerve supplies. These data, as well as data from gene expression analysis, strongly suggest that the transdifferentiation of white-to-brown adipocytes is the major phenomenon driving this transformation of omental fat in pheo-patients.

\section{Material and methods}

\subsection{Subjects}

Omental adipose tissue was removed from 20 control subjects undergoing surgery at the General Hospital Azienda Ospedaliero Universitaria (AOU; Ancona, Italy) for cholecystectomy. The subjects comprised 10 males and 10 females, aged from 32 to 65 years (average 46) with body mass index (BMI) from 18 to 29. The patients affected by adrenal pheochromocytoma included in this study totaled 12: 6 males and 6 females, ranging in age from 29 to 70 years (average 49) and in BMI, from 19 to 30.5. All of them underwent surgery for total resection of the tumor, and samples of omental fat were collected in comparable areas. The clinical details of the subjects are summarized in Table 1.

At the time of the surgery, all subjects had fasted for 15-18 h and had stopped all pharmacological treatment the day before. Informed consent was obtained from the subjects before the surgical procedure. The study protocol was approved by the Ethical Committee (Permission n. 209148) of the University of Ancona (Politecnica delle Marche).

\subsection{Light microscopy (LM)}

Immediately after removal, tissue pieces representing omental adipose tissue were fixed overnight by immersion at $4{ }^{\circ} \mathrm{C}$ in $4 \%$ paraformaldehyde in $0.1 \mathrm{M}$ phosphate buffer ( $\mathrm{pH} 7.4$ ). The samples were then dehydrated, cleared, and embedded in paraffin. Sections from 3 different levels (100 $\mu \mathrm{m}$ apart) were hematoxylin and eosin-stained to assess their morphology, immunohistochemistry and morphometry. All observations were performed with a Nikon Eclipse 80i light microscope (Nikon, Tokyo, Japan) equipped with a CCD camera.

\subsection{Immunohistochemistry (IHC)}

UCP1, tyrosine hydroxylase (TH) and Ki67 (a cellular marker for proliferation) immunostaining were performed as follows. For each $3-\mu \mathrm{m}$-thick section level, dewaxed sections were incubated with anti-UCP1 (1:500; ab10983, Abcam, Cambridge UK), anti-TH (1:300; AB1542 Chemicon Millipore, Milan, Italy) or anti-Ki67 (1:3000; NCL-Ki67p, Novocastra Lab, Newcastle, UK), according to the avidinbiotin complex (ABC) method, briefly 1) endogenous peroxidase blocking with $3 \%$ hydrogen peroxide in methanol; 2) normal serum (1:75) for 20 min to reduce nonspecific background; 3 ) incubation with primary antibodies against UCP1, TH or Ki67 overnight at $4{ }^{\circ} \mathrm{C} ; 4$ ) secondary antibodies specific for each species in which the primary antibody was raised: IgG biotin conjugated (1:200; Vector Labs, Burlingame, CA, USA); 5) ABC kit (Vector Labs); and 6) enzymatic reaction to reveal peroxidase with Sigma Fast 3,3'-diaminobenzidine (Sigma-Aldrich, St. Louis, MO, USA) as the substrate. Finally, sections were counterstained with hematoxylin and mounted in Eukitt (Fluka, Deisenhofen, Germany).

IHC for PRDM16 (1:150; ab3789, Abcam, Cambridge UK) was performed with the same technique described above, and an antigen retrieval step using sodium citrate buffer (10 mM sodium citrate, $0.05 \%$ Tween 20, pH 6.0) was added before blocking with normal serum.

\subsection{Morphometry}

The 3- $\mu$ m-thick sections stained were measured by live count command in Lucia Imaging for image analysis (version 4.82, Nikon Instruments, Florence, Italy).

The area of the TH-ir nerve fibers was measured in the 4 subjects showing at least $10-15 \%$ UCP1-ir adipocytes, based on images randomly captured with a Nikon DXM 1200 camera at $\times 100$. Ten areas in the adipose lobules containing mixed brown/white adipocytes (pheo-patients) and 10 areas of pure white adipocytes (controls) were analyzed. The results are given as the total TH-ir area. The vascular area was measured in semi-thin sections from the same cases using images captured at $40 \times$ objective. The results are given as the total vascular area $/ \mathrm{mm}^{2}$.

Quantitative data on the density of precursor cells (preadipocytes) were produced as the number of cells per 100 capillaries. 
Table 1

Clinical data of subjects included in the study.

\begin{tabular}{|c|c|c|c|c|c|}
\hline Patient ID & Age/gender & BMI $\left(\mathrm{kg} / \mathrm{m}^{2}\right)$ & Pathology/reason for surgery & position/size diameter & UCP1-ir adipocytes \\
\hline CTRL-1 & $65 / \mathrm{M}$ & 29 & Gallstones/cholecystectomy & & Neg \\
\hline CTRL-2 & $34 / \mathrm{M}$ & 24 & Gallstones/cholecystectomy & & Neg \\
\hline CTRL-3 & $45 / \mathrm{M}$ & 28 & Gallstones/cholecystectomy & & Neg \\
\hline CTRL-4 & $53 / \mathrm{F}$ & 18 & Gallstones/cholecystectomy & & Neg \\
\hline CTRL-5 & $52 / \mathrm{F}$ & 25 & Gallstones/cholecystectomy & & Neg \\
\hline CTRL-6 & $55 / \mathrm{M}$ & 25 & Gallstones/cholecystectomy & & Neg \\
\hline CTRL-7 & $36 / \mathrm{M}$ & 26 & Gallstones/cholecystectomy & & Neg \\
\hline CTRL-8 & $59 / \mathrm{M}$ & 29 & Gallstones/cholecystectomy & & Neg \\
\hline CTRL-9 & $58 / \mathrm{M}$ & 26 & Gallstones/cholecystectomy & & Neg \\
\hline CTRL-10 & $41 / \mathrm{M}$ & 21 & Gallstones/cholecystectomy & & Neg \\
\hline CTRL-11 & $40 / \mathrm{M}$ & 22 & Gallstones/cholecystectomy & & Neg \\
\hline CTRL-12 & $38 / F$ & 29 & Gallstones/cholecystectomy & & Neg \\
\hline CTRL-13 & $64 / F$ & 24 & Gallstones/cholecystectomy & & Neg \\
\hline CTRL-14 & $32 / \mathrm{F}$ & 23 & Gallstones/cholecystectomy & & Neg \\
\hline CTRL-15 & $51 / \mathrm{F}$ & 25 & Gallstones/cholecystectomy & & Neg \\
\hline CTRL-16 & $45 / F$ & 28 & Gallstones/cholecystectomy & & Neg \\
\hline CTRL-17 & $60 / F$ & 28 & Gallstones/cholecystectomy & & Neg \\
\hline CTRL-18 & $47 / \mathrm{M}$ & 21 & Gallstones/cholecystectomy & & Neg \\
\hline CTRL-19 & $52 / \mathrm{F}$ & 26 & Gallstones/cholecystectomy & & Neg \\
\hline CTRL-20 & $50 / \mathrm{F}$ & 27 & Gallstones/cholecystectomy & & Neg \\
\hline Pheo-1 & $33 / \mathrm{F}$ & 21.5 & Pheochromocytoma/resection & $\mathrm{Sx} / 5 \mathrm{~cm}$ & ++++ \\
\hline Pheo-2 & $64 / \mathrm{F}$ & 25 & Pheochromocytoma/resection & $\mathrm{Sx} / 4 \mathrm{~cm}$ & +++ \\
\hline Pheo-3 & $70 / \mathrm{M}$ & 30.5 & Pheochromocytoma/resection & $\mathrm{Dx} / 5.5 \mathrm{~cm}$ & + \\
\hline Pheo-4 & $38 / F$ & 26.7 & Pheochromocytoma/resection & $\mathrm{Dx} / 3 \mathrm{~cm}$ & Neg \\
\hline Pheo-5 & $50 / \mathrm{M}$ & 23.7 & Pheochromocytoma/resection & $\mathrm{Dx} / 3.5 \times 4 \times 2 \mathrm{~cm}$ & Neg \\
\hline Pheo-6 & $58 / \mathrm{M}$ & 23 & Pheochromocytoma/resection & $\mathrm{Dx} / 6.5 \times 6 \times 3 \mathrm{~cm}$ & Neg \\
\hline Pheo-7 & $38 / F$ & 26 & Pheochromocytoma/resection & $\mathrm{Sx} / 4 \mathrm{~cm}$ & + \\
\hline Pheo-8 & $29 / F$ & 19.5 & Pheochromocytoma/resection & $\mathrm{Dx} / 3 \times 2 \mathrm{~cm}$ & ++ \\
\hline Pheo-9 & $45 / \mathrm{F}$ & 19 & Pheochromocytoma/resection & $\mathrm{Dx} / 4 \mathrm{~cm}$ & ++ \\
\hline Pheo-10 & $64 / \mathrm{M}$ & 28 & Pheochromocytoma/resection & $\mathrm{Sx} / 5 \mathrm{~cm}$ & Neg \\
\hline Pheo-11 & $50 / \mathrm{M}$ & 25 & Pheochromocytoma/resection & $\mathrm{Sx} / 3 \mathrm{~cm}$ & Neg \\
\hline Pheo-12 & $52 / \mathrm{M}$ & 27 & Pheochromocytoma/resection & $\mathrm{Dx} / 3 \times 2 \mathrm{~cm}$ & Neg \\
\hline
\end{tabular}

\subsection{Transmission electron microscopy (TEM)}

Immediately after removal, small fragments of the tissues were fixed in $2 \%$ glutaraldehyde- $2 \%$ paraformaldehyde in $0.1 \mathrm{M}$ phosphate buffer ( $\mathrm{pH} \mathrm{7.4)}$ ) for at least $4 \mathrm{~h}$, postfixed in 1\% osmium tetroxide, and embedded in an Epon-Araldite mixture. Semi-thin sections $(2 \mu \mathrm{m})$ were stained with toluidine blue. Thin sections were obtained with an MT-X ultratome (RMC, Tucson, AZ, USA), stained with lead citrate, and examined with a CM10 transmission electron microscope (Philips, Eindhoven, The Netherlands).

\subsection{Real time $P C R(q P C R)$ analysis}

qPCR experiments were performed on omental fat samples from 4 controls and 4 pheo-patients. Fragments of tissue were harvested from the same samples used for morphological evaluation, washed in Dulbecco's PBS, snap frozen and immediately stored at $-80{ }^{\circ} \mathrm{C}$. The total RNA was extracted using the TRIZOL reagent (Invitrogen, Monza, Italy), purified, digested with a ribonuclease-free deoxyribonuclease and concentrated using RNeasy Micro kit (Qiagen, MI, Italy), according to the respective manufacturers' instructions.

For the determination of mRNA levels, $1 \mu \mathrm{g}$ of RNA was reversetranscribed with a High-Capacity cDNA RT Kit with RNase Inhibitor (Applied BioSystems, Foster City, CA) in a total volume of $20 \mu \mathrm{l}$. qPCR gene expression was performed in triplicate using TaqMan Gene Expression Assays (Applied BioSystems, CA, USA) as listed: UCP1: Hs00222453_m1; PRDM16: Hs00223161_m1; Dio2: Hs00255341_m1, TATA-box binding protein: Hs00427621_m1; PGC1 $\alpha$ : Hs01016719_m1; Adrenoceptor beta 3 (ADRB3): Hs00609046_m1 and TaqMan Master Mix (Applied BioSystems, CA, USA).

Reactions were carried out in an ABI 7300 system (Applied Biosystems) using $50 \mathrm{ng}$ of RNA for a final reaction volume of $20 \mu \mathrm{l}$ and performing the following thermal cycle protocol: initial incubation at $95{ }^{\circ} \mathrm{C}-10 \mathrm{~min}$, followed by 40 cycles of $95^{\circ} \mathrm{C}-15 \mathrm{~s}$ and $60{ }^{\circ} \mathrm{C}$ $-20 \mathrm{~s}$.

For each reaction, the reverse transcriptase was omitted in the amplification mixture during the RT-PCR to rule out genomic contamination and used as a negative control.

The relative mRNA expression was determined by the standard curve method using TATA box-Binding Protein (TBP) levels as endogenous controls. Differences in the starting total RNA and different efficiencies of cDNA synthesis among samples were normalized using TBP expression, and the results were reported in arbitrary units.

\subsection{Statistical analysis}

The results are given as the means \pm SE if not otherwise stated. The differences among group means were analyzed by Mann-Whitney $U$ test and considered significant when $P \leq 0.05$.

\section{Results}

\subsection{Remodeling of human WAT under adrenergic stimulation}

To establish if the omental fat depot of pheo-patients undergoes a process of browning, as hypothesized by FDG-PET studies [32,33], we performed a careful examination at the morphological level and a comparison with tissues obtained from the same depot in control subjects (Fig. 1A). The first striking evidence was reported by light microscopy and then emphasized by immunohistochemistry after the visualization of UCP1 was performed. In half ( 6 subjects) of the patients examined, we found UCP1-ir multilocular cells and in particular, we identified BAT islands among WAT in four of them (Fig. 1B). In these four cases, the vast majority of UCP1-ir cells showed the classic morphology of brown adipocytes: small cells with small numerous cytoplasmic uniform vacuoles (Fig. 1B). A considerable proportion 

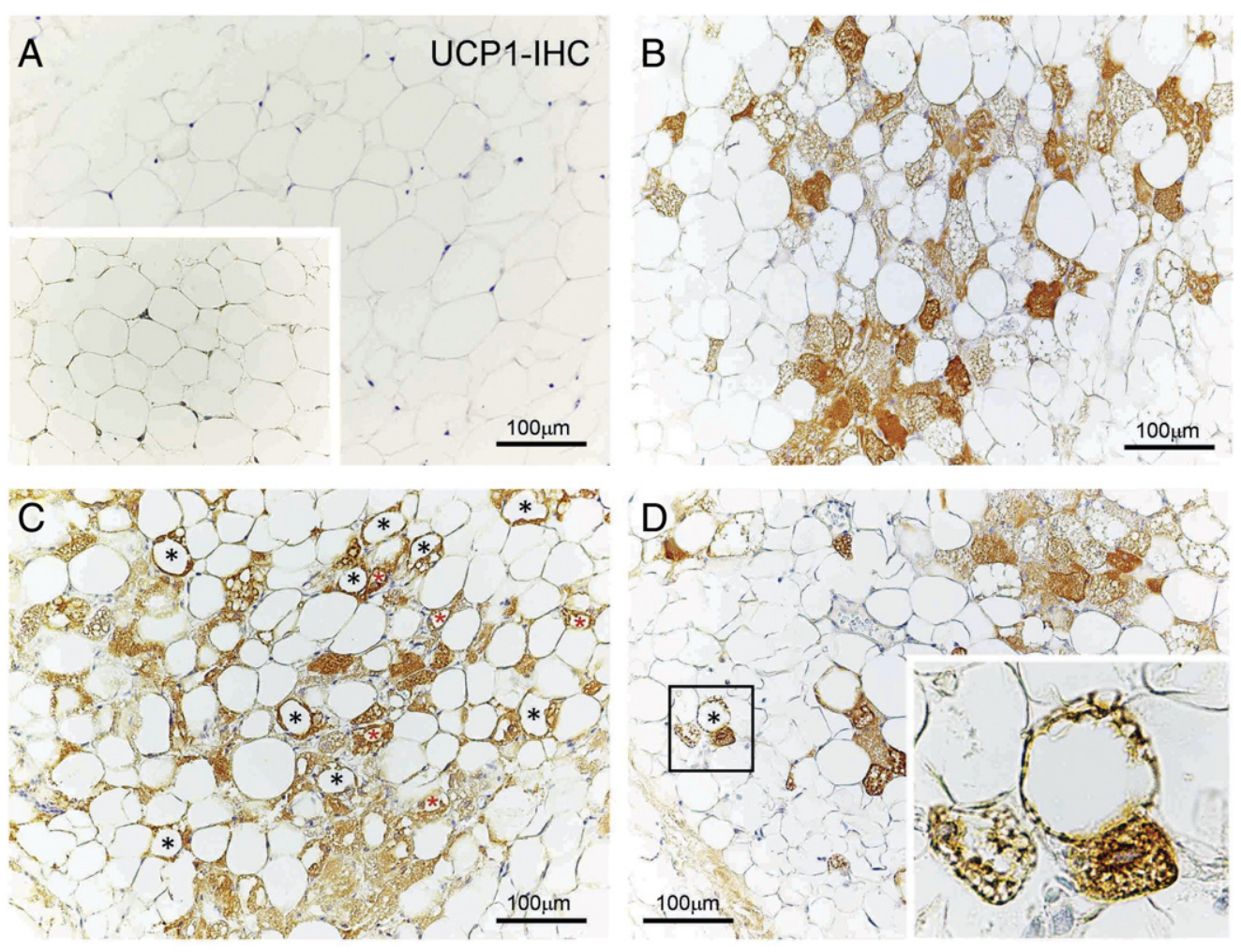

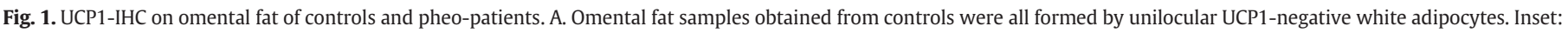

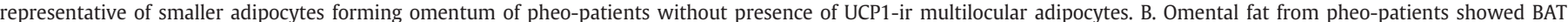

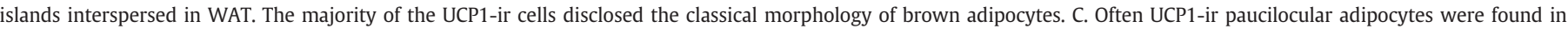

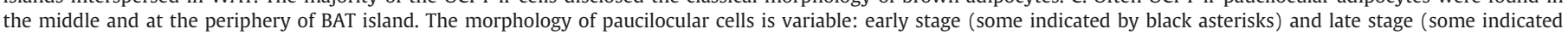
by red asterisks) of transdifferentiation. D. Some paucilocular cells were found interspersed among white adipocytes. The inset is an enlargement of the black squared area.

(ranging from $20 \%$ to $30 \%$ ) of UCP1-ir cells displayed a predominant large fat vacuole with numerous small fat droplets at the periphery of the cytoplasm ("paucilocular adipocytes", Fig. 1C asterisks), and these variants were located within the brown-fat islands, most prominently at the periphery but also interspersed among the unilocular white adipocytes (inset in Fig. 1D). In the other two cases, UCP1-ir adipocytes were rare and interspersed among white adipocytes and with the above-described morphology of paucilocular cells.

The other half of the samples (6 subjects) obtained from pheopatients did not show drastic changes in the morphology of the depot but did demonstrate a reduction of adipocyte area, which was visually evident (inset in Fig. 1A) compared with the unilocular white adipocytes that formed the omental fat of controls (32.2\% reduction was calculated by morphometry).

Ultrastructural examination of the BAT islands performed by TEM (Fig. 2B) confirmed the classical appearance of brown adipocytes with the characteristic large round-shaped mitochondria, endowed with numerous laminar cristae (inset in Fig. 2B); in the white adipocytes of the control tissues, the mitochondria were small and elongated, with randomly oriented cristae (Fig. 2A arrows). Notably, ultrastructural examination highlighted increased mitochondrial density in paucilocular cells (Fig. 2C). In some multilocular adipocytes, the mitochondrial morphology was intermediate between that found in unilocular and in multilocular adipocytes; i.e., the mitochondria exhibited an intermediate white-brown morphology (Fig. 2C, W/B).

In mice, the browning phenomenon is accompanied by a tissue re-arrangement, mainly due to the increase in noradrenergic fibers and capillary density. To examine whether this tissue re-organization also occurs in the brown-fat areas found in these samples, we examined tissue sections for the presence and density of the adrenergic nerve marker tyrosine hydroxylase (TH). We analyzed white-fat areas and brown-fat islands in 4 subjects with abundant brown adipocytes and compared these samples with 4 controls. There were practically no visible adrenergic nerve fibers $\mathrm{TH}-\mathrm{ir}$ in the control tissues (Fig. 3A). However, in the brown islands present in the omental fat of pheo-patients, the density of TH-ir fibers was significantly higher (Fig. B), both at the perivascular position (Fig. 3C) and in the tissue parenchyma (Fig. 3D).

A quantitative analysis of the capillary density showed a significant increase in the omental fat of pheo-patients (Fig. 3E).

To note, two of the pheo-patients in which a large transformation of the tissue was observed have low BMI (see details in Table 1). Since the presence of BAT in adult humans has been related to lower BMI in several studies [9-13] we considered also this parameter in the overall evaluation. However, some pheo-patients with comparable low BMI did not show the presence of UCP1-ir adipocytes. Thus we were unable to find any correlation with clinical parameters within this small cohort of patients.

\subsection{PRDM16 is expressed in the development and transformation of paucilocular and multilocular adipocytes of the omentum in pheo-patients}

To further characterize the newly appearing brown adipocytes, IHC against PRDM16 was performed. PRDM16-IHC in the omental fat of pheo-patients clearly stained in the nuclei of many multilocular cells (Fig. 4A, B black arrows). However, some multilocular cells were slightly positive (Fig. 4B black arrowhead) or even negative, whereas all paucilocular cells were strongly positive in their nuclei. Small multilocular cells with features consistent with poorly differentiated adipocytes (late preadipocytes) were also immunostained (Fig. 4D).

Unilocular white adipocytes and all other cell types (used as internal negative controls) were found to be negative in pheo-patients (Fig. 4A) and in controls. 


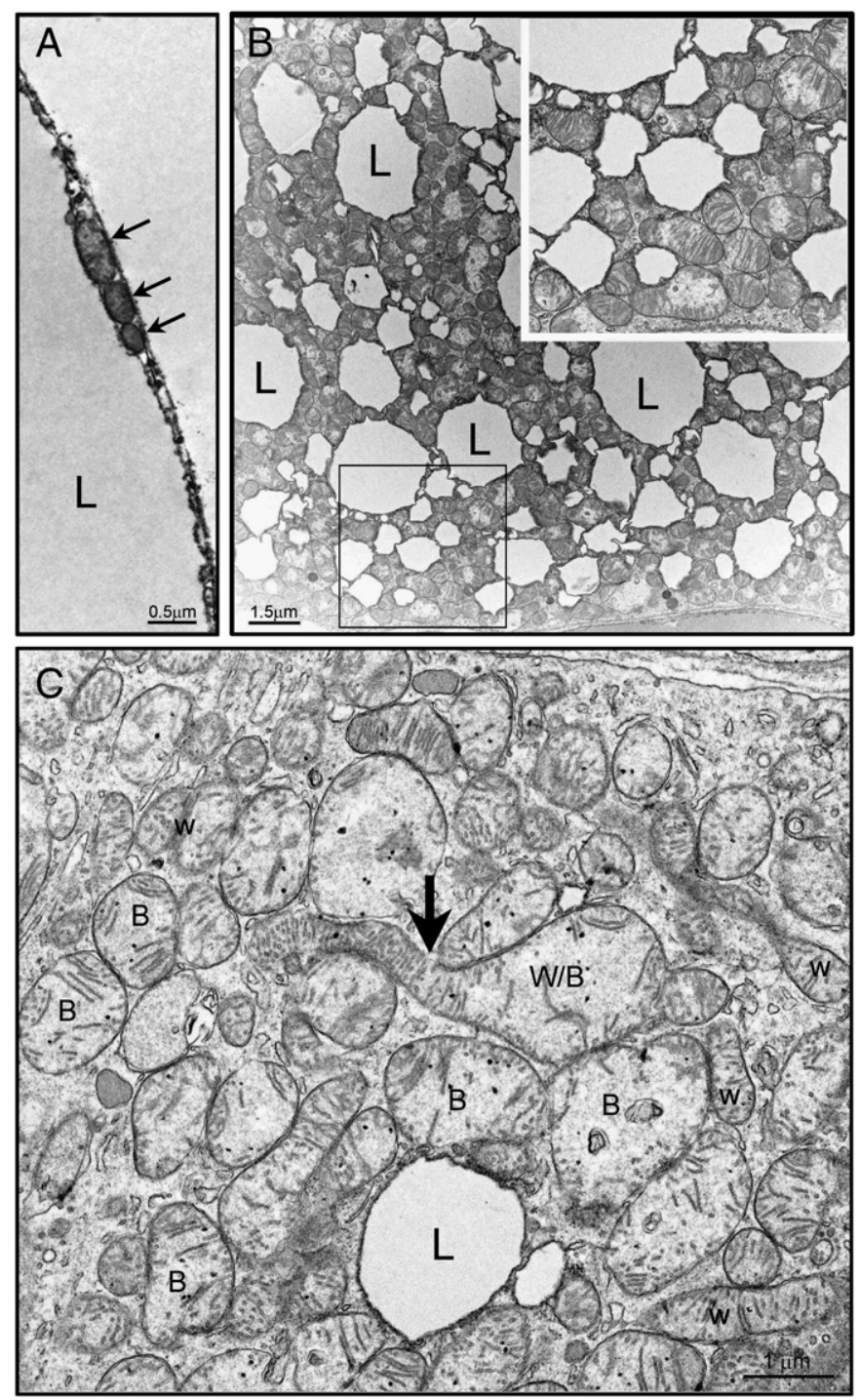

Fig. 2. TEM appearance of brown adipocytes found in omental fat of pheo-patients. A. White adipocytes present in control omentum are endowed with small mitochondria (arrows). B. Multilocular adipocytes present in BAT-like tissue of omentum of pheo-patients. The inset is an enlargement of the black squared area showing the characteristic morphology of large rounded shaped "brown" mitochondria with numerous and packed cristae, as described in BAT. C. Enlargement of a paucilocular cell periphery showing increased mitochondrial density. Of note, brown-like (same indicated by B) as well as white-like mitochondria (some indicated by $\mathrm{W}$ ) are present in the same cell. A white/brown mitochondrion is also visible (W/B). The transition between the white part and the brown part is indicated by arrow. L: lipid droplet.

\subsection{Evaluation of the presence of precursor cells in the omental fat of} controls vs pheo-patients

Electron microscopy provides an easy and specific recognition of adipocyte precursors both in WAT and BAT and also during the development of these tissues $[13,35,36]$. Thus, we used our substantial experience in this field to evaluate the preadipocyte density in the pericapillary position by quantitative electron microscopy in order to evaluate potential differences in the number of precursor cells between patients and controls and found that there was no significant increase in the omental fat of pheo-patients (Fig. 5). We considered all poorly differentiated cells (i.e. with high nucleus:cytoplasm ratio and with small and not completely developed organelles) surrounded by a distinct basal membrane located in the capillary wall in a pericytic position as preadipocytes (Fig. 5 lower panel).
In support of these data, which suggest a lack of important proliferative phenomena, the immunohistochemistry performed for Ki67 showed a negligible number of immunostained nuclei in omental fat obtained from pheo-patients and controls (Supplementary Fig. S1).

\subsection{Gene expression analysis showed the up-regulation of brown fat genes even in the absence of detectable morphological evidence of browning}

The morphological transformation of the tissue toward a brown-like phenotype was accompanied by a robust increase in the expression of some brown fat-selective genes, such as UCP1, PRDM16, and ADRB3 (Fig. 6).

All of the "brown" genes examined showed a general up-regulation trend in the omentum of pheo-patients vs controls, as follows: UCP1 (14.7-fold), PRDM16 (4.5-fold) and ADRB3 (26.5-fold). Each was significantly higher than controls, whereas the other two genes analyzed, PCG1 $\alpha$ (3.68-fold) and DIO2 (3.27-fold), were expressed at higher but not significant levels. It is worth noting that the brown fat gene expression was found to be up-regulated, albeit to a lesser extent, even in those tissue samples where the morphology had not drastically changed compared to controls.

\section{Discussion}

In the last 5 years, BAT has become one of the most investigated targets of researchers working in the field of metabolism who hope to find a mechanism to recruit and activate this tissue in conditions of impaired energy homeostasis. Because weight gain is always caused by chronic energy imbalance, nonsurgical therapies for obesity must reduce the energy intake and/or increase the energy expenditure. BAT activity appears to be higher in lean than in obese subjects [37] and correlates with resting metabolic rate [38-40]; this research suggests that BAT may be an as-yet-unrecognized regulator of adult human metabolism and energy expenditure.

However, most of the information available regarding the morphology and biology of this tissue has been obtained in rodents. In the adult mice of two different strains (Sv129 and C57B6J), the individual depots forming the whole adipose organ have a "whitebrown" mixed composition [27]. The depots that include more brown adipocytes were the mediastinic depots, while more white adipocytes were localized in the mesenteric depots. Under thermoneutral conditions, the presence of brown adipocytes is 5 times higher in the obesity-resistant Sv129 strain. However, in both strains, specific subcutaneous and visceral depots are densely packed with brown adipocytes, including the interscapular area of the anterior subcutaneous depot, the periaortic area of the mediastinic depot and the inter-renal area of the abdomino-pelvic depot. Brown adipocytes located in interscapular and perirenal areas seem to have the same embryonic origin, sharing the expression of the Myf5 gene with myoblasts derived from paraxial mesoderm [18]. Of note, mediastinic brown adipocytes were not studied in the original paper by Seale et al. [18] Thus, we cannot distinguish brown adipocytes in the interscapular area from those in the inter-renal area on the basis of Myf5 lineage in addition to their morphology and physiology. As a result, we tend to consider all UCP1-ir multilocular cells in the adipose organs as true brown adipocytes.

After adrenergic stimuli (cold exposure or $\beta 3$-agonist), the number of brown adipocytes in the adipose organ increased in both strains. Importantly, this increase in brown adipocytes was shown to coincide quantitatively with a reduction in white adipocytes.

This phenomenon is usually referred to as "browning" and has been observed in a large number of knockout (KO) or transgenic strains that show resistance to diet-induced obesity and an improved glucose metabolism $[4,15,41-47]$. On the other hand, the disappearance of BAT 

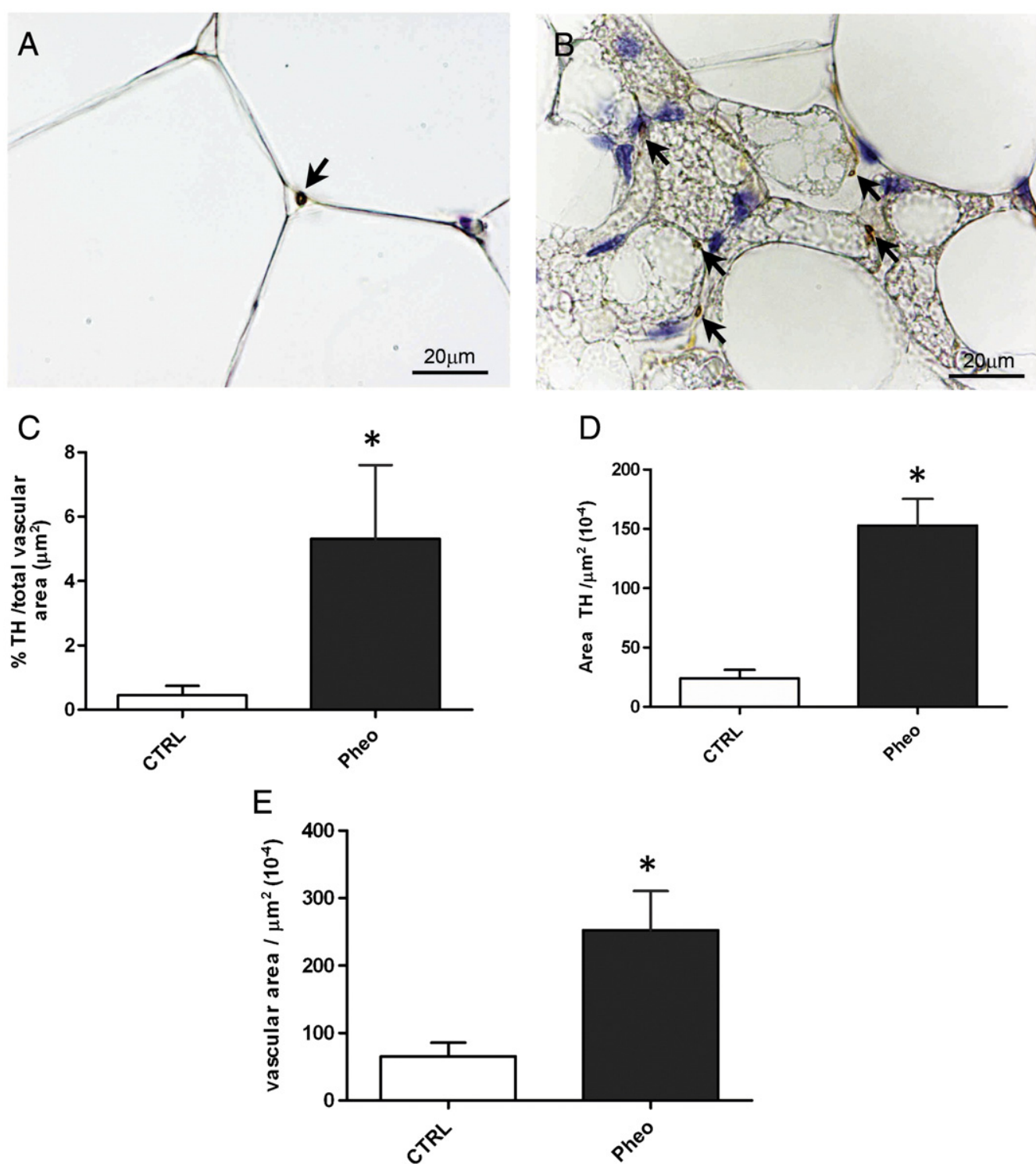

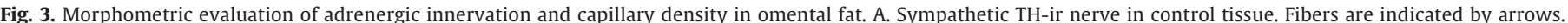

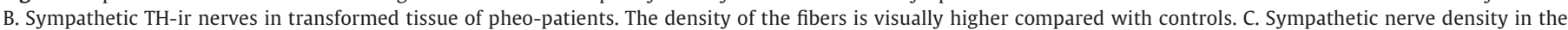

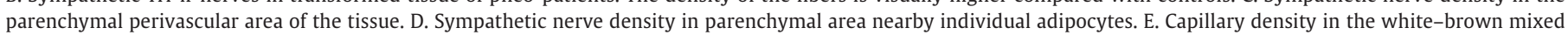
tissue of omental fat found in pheo-patients.

was accompanied with severe obesity in mice with food intake and physical exercise comparable to those of controls [6]. Thus, the browning of the adipose organ can be useful in combating obesity and related disorders.

The origin of newly appearing brown adipocytes is debated and seems to differ according to depots. Data from our laboratory and others suggest that most of the newly formed brown adipocytes derive from a direct transformation of white adipocytes (transdifferentiation) $[21,22,28,48,49]$.

In humans, only a small amount of metabolically active brown adipocytes is detectable by PET, mainly in young subjects and after cold exposure [11,12]. The areas of the human adipose organ that are PET-positive and correspond histologically to UCP1-ir brown adipocytes are located in close proximity to the subclavian and carotid arteries [10,13]. Histology has shown that, in these areas, UCP1-ir brown adipocytes are mixed with white adipocytes, recalling the mixed distribution found in mice. After hyper-adrenergic stimulation (pheochromocytoma), PET analysis studies have shown an intense browning of the adipose organ with a distribution of metabolically active brown adipocytes comparable to that found in mice, i.e., surrounding the aorta and all of its main branches (mainly subclavian, carotids, intercostals and perirenal arteries) [32,33]. This location most likely allows a quick distribution of the heat produced by the activated BAT to the rest of the body. These sites correspond to the subcutaneous and visceral fat depots found in mice that are enriched with brown adipocytes [1]. The only exception is the interscapular area, which is not present in adult humans [8]. Perhaps small mammals, with their lesser body volumes and thus high thermodispersion, require additional brown sites. Of note, thermo-dispersion also requires larger vessels to allow for heat distribution; in fact, the interscapular BAT occurs in proximity to a large vein (of Sulzer) that is not present in humans.

Recently, a paper showed PET-positive areas in the omentum of a pheo-patient for the first time [50], opening the possibility that even pure white adipocytes, located in canonical WAT sites and never having been mixed with brown adipocytes, have the potential for transformation into brown adipocytes. The possibility of increasing the number of brown adipocytes in the adipose organ of humans, thus 

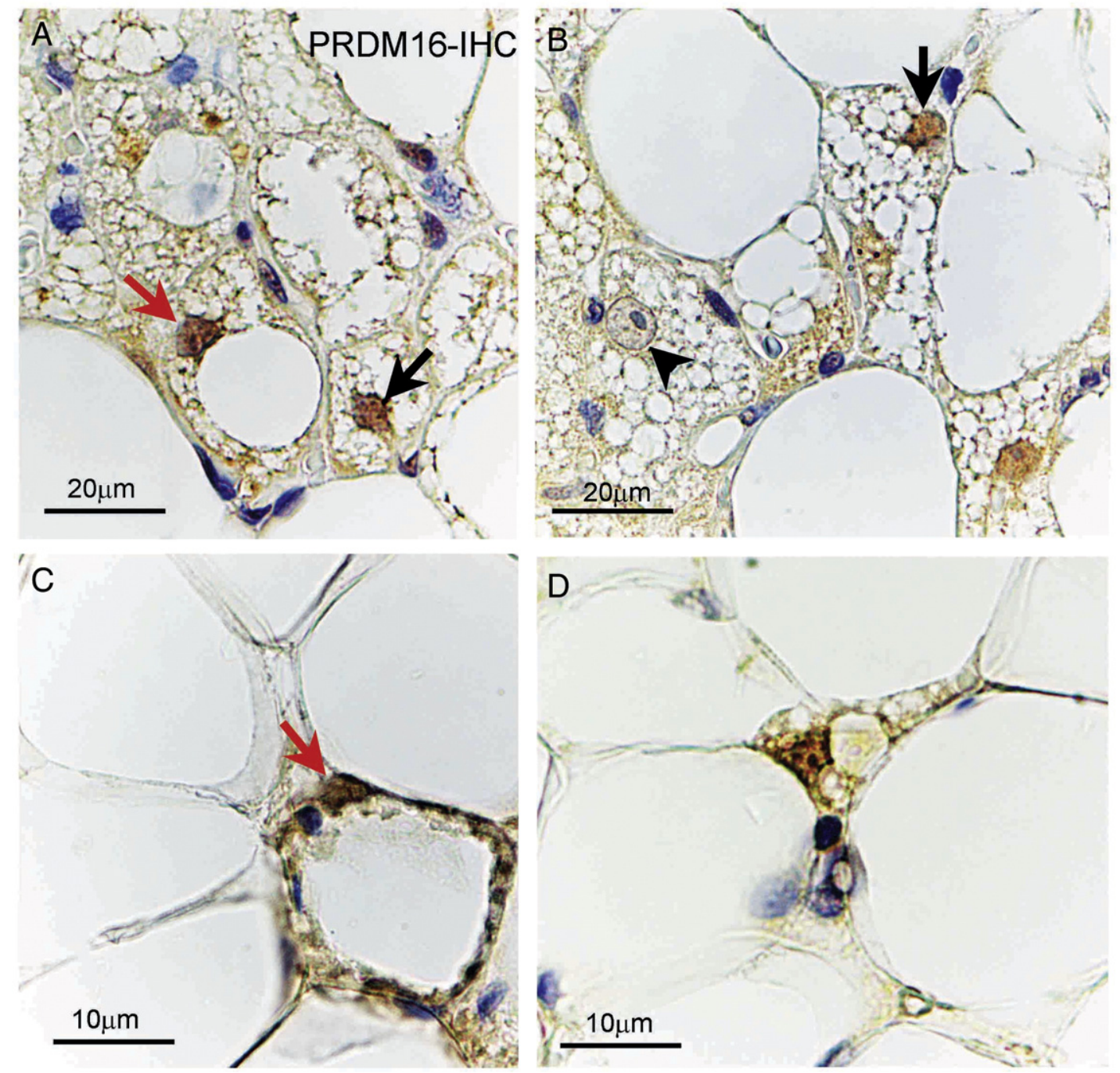

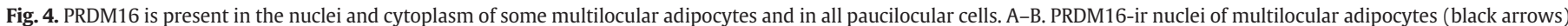

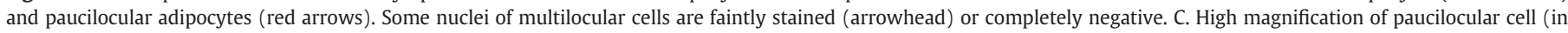

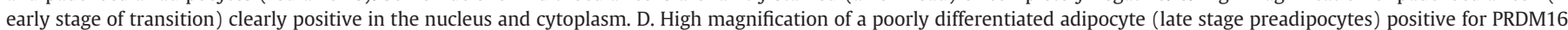

converting true WAT into BAT-like, is an attractive prospect for the treatment of obesity and related disorders.

The data obtained showed that, in half of the cases, a browning of the tissue was evoked under these conditions with the appearance of UCP1-ir brown adipocytes. Interestingly, all other patients showed a reduction in the size of their unilocular adipocytes anyway; this is suggestive of an early step in remodeling. Gene expression analysis supports this interpretation, as the "brown" genes were up-regulated even in the tissues without histological signs of browning. PGC1 $\alpha$ was not significantly increased in the pheo-omental tissues or in other murine models of WAT browning [42,51]. A post-transcriptional regulation has been proposed in mice [51] and could also be required in this model. The ADRB3 increase was in line with the IHC data of a previous study in which we found intense immunoreactivity in multilocular adipocytes located in the peri-adrenal fat in two cases of pheochromocytoma [52]. The different remodeling of the omentum in single patients of the case series described here could be related to several factors, such as age of patients and the size and activity of the adrenal tumor. The scarce number of cases does not allow for any specific correlation.

The cellular process underlying the browning of the omentum in pheo-patients seems to be similar to the process occurring in mice after adrenergic stimuli. In fact, the cells we consider as morphologic markers of transdifferentiation (paucilocular UCP1-ir brown adipocytes) were present in all cases. Of note, several steps in morphogenesis are necessary to complete the process of the transformation of unilocular adipocytes into multilocular adipocytes; the step through which intermediate cells assume the expression of the marker protein UCP1 must be included [22]. Sometimes, UCP1 is expressed early in this process, and we were able to identify this early step (see Fig. 1C), which is strongly indicative for a direct transformation. Electron microscopy showed not only the typical features of paucilocular cells but even "transforming" mitochondria with morphology at an intermediate stage between that of white and brown. Of note, similar mitochondria were found in human brown adipocytes during primary cultures. These brown adipocytes, maintained in standard adipogenic conditions, showed a progressive loss of brown phenotype in their mitochondria; by the intermediate steps of culturing, they already had white-like and brown-like mitochondria at the same time in their cytoplasm [53].

The quantitative data on preadipocyte density showed only a tendency to increase; thus, the contribution of developmental and proliferative events in line with the absence of a significant number of Ki67-immunostained nuclei in the omentum of pheo-patients is unlikely to be important. However, we cannot completely exclude the contribution of specific sub-population of cells, present in the stromal vascular fraction and participating in the remodeling of the tissue.

Nonetheless, the adrenergic environment in the pheo-omentum seems to be sufficient to designate a brown phenotype for preadipocytes, as revealed by electron microscopy and supported by 

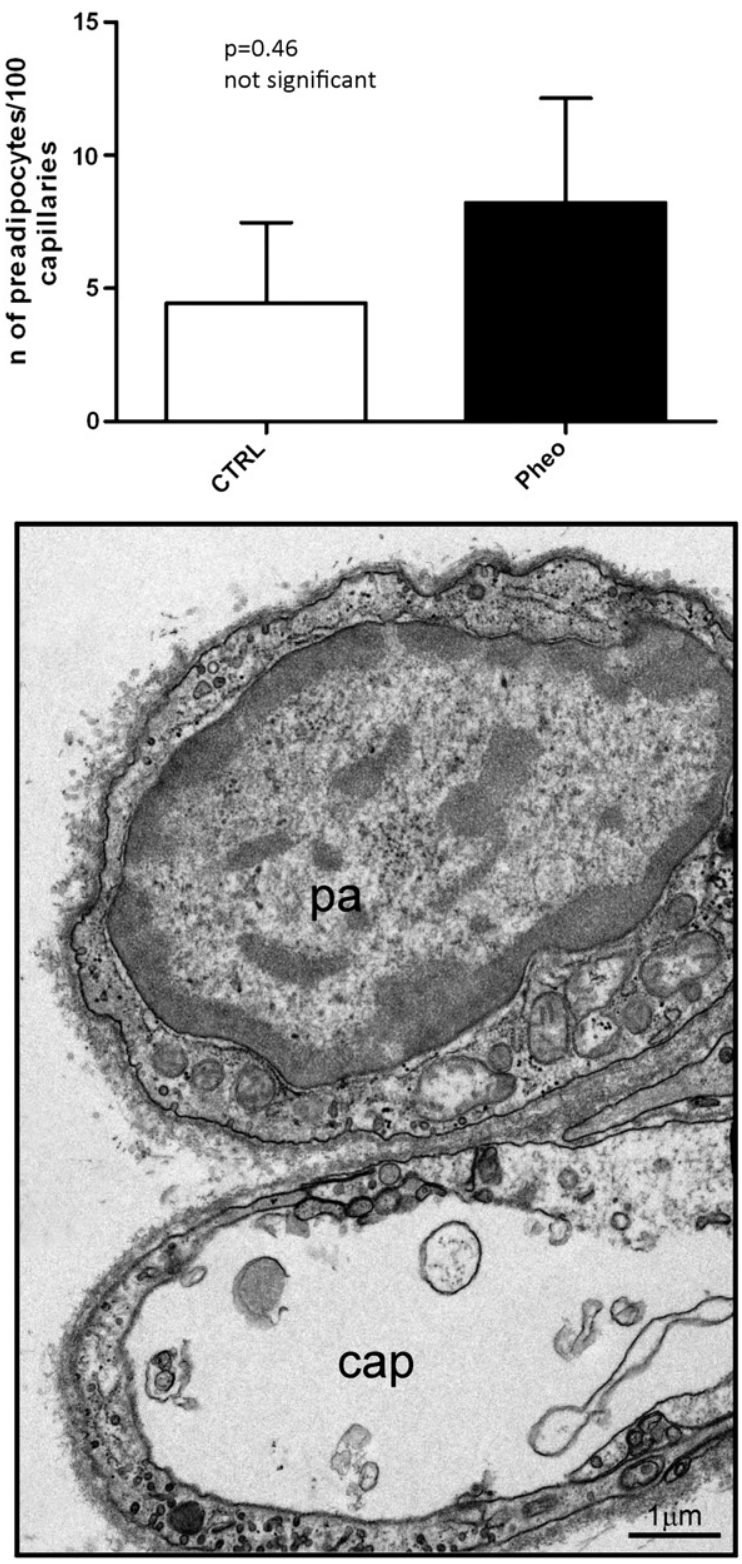

Fig. 5. Presence and density of precursor cells in the omental fat of control vs pheopatients. Morphometric evaluation showed a not significant difference in the number of precursors cells found in omental fat of controls vs pheo-patients. Preadipocytes (pa) were visualized as small cells with high nucleus:cytoplasm ratio and with poorly differentiated organelles. They are always surrounded by a distinct basal membrane located in the capillary (cap) wall in a pericytic position.

immunodetection of the poorly differentiated multilocular cells (late preadipocytes) of PRDM16. The nuclei of the transforming adipocytes (paucilocular adipocytes) and of multilocular adipocytes with classic morphology were intensely stained for PRDM16; however, some of the multilocular adipocytes were only faintly stained or negative. Overall, these data suggest that PRDM16 is in fact an important brown-determining factor that plays a role during brown development and white-to-brown transdifferentiation. After the brown phenotype has been acquired, PRDM16 seems to lose its importance. In support of this idea is the fact that transgenic mice hyperexpressing PRDM16 (aP2-PRDM16 mice) induce the browning of WAT while having no effect on BAT [17].

The recent description of the molecular markers characteristic of UCP1-ir multilocular adipocytes, which were found in different anatomical fat depots that have usually been considered prevalently white and in these cases are described as brite/beige fat cells, raises

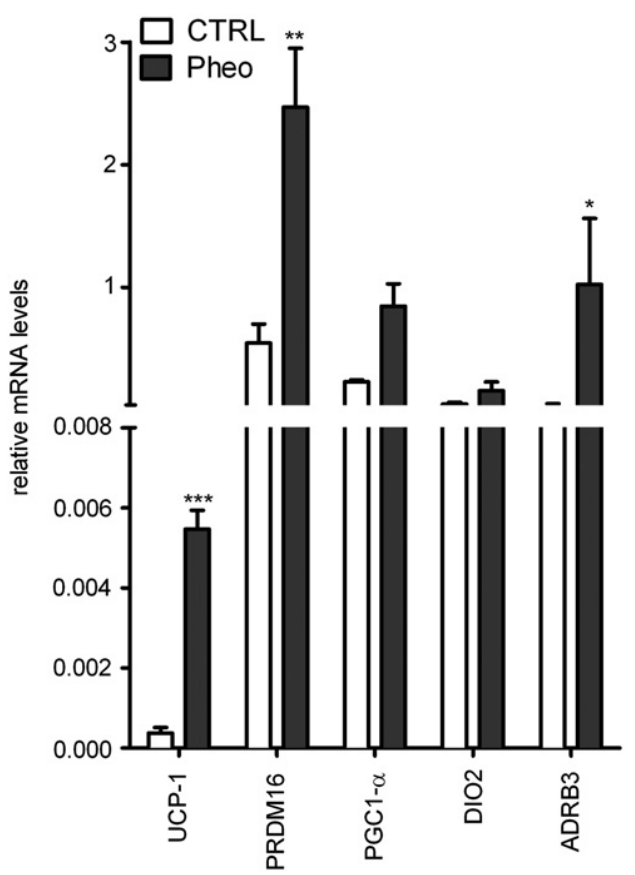

Fig. 6. Brown gene expression in omental fat. Relative mRNA expressions of UCP1, PRDM16 and ADRB3 were significantly up-regulated in the omentum of pheo-patients. ${ }^{*} \mathrm{p} \leq 0.01 ;{ }^{* *} \mathrm{p} \leq 0.01 ;{ }^{* * *} \mathrm{p} \leq 0.001$.

the possible existence of different subtypes of brown adipocytes in mice and humans $[23,25,54]$.

Further studies are required to identify the function of the brite/ beige genetic markers in order to verify any physiological properties at the single cell level that may eventually differ from those of the brown adipocytes found in "classical" anatomical locations (iBAT in mice and cervical in humans, i.e., anatomical areas where brown adipocytes are resistant to age-induced BAT-to-WAT transformation). At the moment, the widespread distribution of brown adipocytes in the adipose organ does not support, in our opinion, a different denomination for these UCP1-ir multilocular adipocytes. The recent discovery of unilocular adipocytes with a Myf5 lineage [55], together with the data presented here in humans and elsewhere in rats and mice $[21,22,50]$, support the possibility of the direct transformation of white adipocytes into brown. The molecular mechanism underlying this transdifferentiation has been linked to ADRB3 [6,22,50,56,57], and therapeutic strategies should bypass these receptors in order to avoid problems linked with adrenergic side effects on the cardiovascular and respiratory systems. These alternative pathways have been rapidly expanding in the recent literature [58] and, interestingly, include new modulators of PPAR $\gamma$ [59], physical exercise [60], especially in association with an enriched environment [61] or even the use of skeletal [62] or atrial [63] myokines or growth factors, such as BMP8b [64] or FGF21 [52,65]. Interestingly, from the preliminary results obtained in a few new samples, we have found FGF21 to be up-regulated in the omental fat of pheo-patients in comparison to the undetectable levels found in controls.

Taken together, the data presented in this study suggest that in adult humans, pure white omental fat subjected to adrenergic stimulation shows a distinct WAT-BAT plasticity. Under these conditions, white adipocytes seem to be able to undergo a process of direct transformation into brown adipocytes, and the whole tissue is exposed to a general rearrangement toward BAT. This could be of clinical importance in opening new avenues for the future treatment of obesity and $\mathrm{T} 2$ diabetes.

Supplementary data to this article can be found online at http:// dx.doi.org/10.1016/j.bbalip.2013.02.005. 


\section{Acknowledgements}

This work was supported by the EU FP7 project DIABAT (HEALTHF2-2011-278373) to S.C.

\section{References}

[1] A. Frontini, S. Cinti, Distribution and development of brown adipocytes in the murine and human adipose organ, Cell Metab. 7 (2010) 253-256.

[2] S. Enerbäck, A. Jacobsson, E.M. Simpson, C. Guerra, H. Yamashita, M.E. Harper, L.P. Kozak, Mice lacking mitochondrial uncoupling protein are cold-sensitive but not obese, Nature 387 (1997) 90-94.

[3] H.M. Feldmann, V. Golozoubova, B. Cannon, J. Nedergaard, UCP1 ablation induces obesity and abolishes diet-induced thermogenesis in mice exempt from thermal stress by living at thermoneutrality, Cell Metab. 9 (2009) 203-209.

[4] J. Kopecky, G. Clarke, S. Enerback, B. Spiegelman, L.P. Kozak, Expression of the mitochondrial uncoupling protein gene from the aP2 gene promoter prevents genetic obesity, J. Clin. Invest. 96 (1995) 2914-2923.

[5] B.B. Lowell, V. S-Susulic, A. Hamann, J.A. Lawitts, J. Himms-Hagen, B.B. Boyer, L.P. Kozak, J.S. Flier, Development of obesity in transgenic mice after genetic ablation of brown adipose tissue, Nature 366 (1993) 740-742.

[6] E.S. Bachman, H. Dhillon, C.Y. Zhang, S. Cinti, A.C. Bianco, B.K. Kobilka, B.B. Lowell, betaAR signaling required for diet-induced thermogenesis and obesity resistance, Science 297 (2002) 843-845.

[7] B.B. Lowell, B.M. Spiegelman, Towards a molecular understanding of adaptive thermogenesis, Nature 404 (2000) 652-660.

[8] J. Nedergaard, T. Bengtsson, B. Cannon, Unexpected evidence for active brown adipose tissue in adult humans, Am. J. Physiol. Endocrinol. Metab. 293 (2007) E444-E452.

[9] A.M. Cypess, S. Lehman, G. Williams, I. Tal, D. Rodman, A.B. Goldfine, F.C. Kuo, E.L. Palmer, Y.H. Tseng, A. Doria, G.M. Kolodny, C.R. Kahn, Identification and importance of brown adipose tissue in adult humans, N. Engl. J. Med. 360 (2009) 1509-1517.

[10] K.A. Virtanen, M.E. Lidell, J. Orava, M. Heglind, R. Westergren, T. Niemi, M. Taittonen, J. Laine, N.J. Savisto, S. Enerbäck, P. Nuutila, Functional brown adipose tissue in healthy adults, N. Engl. J. Med. 360 (2009) 1518-1525.

[11] W.D. van Marken Lichtenbelt, J.W. Vanhommerig, N.M. Smulders, J.M. Drossaerts, G.J. Kemerink, N.D. Bouvy, P. Schrauwen, G.J. Teule, Cold-activated brown adipose tissue in healthy men, N. Engl. J. Med. 360 (2009) 1500-1508.

[12] M. Saito, Y. Okamatsu-Ogura, M. Matsushita, K. Watanabe, T. Yoneshiro, J. Nio-Kobayashi, T. Iwanaga, M. Miyagawa, T. Kameya, K. Nakada, Y. Kawai, M. Tsujisaki, High incidence of metabolically active brown adipose tissue in healthy adult humans: effects of cold exposure and adiposity, Diabetes 58 (2009) 1526-1531.

[13] M.C. Zingaretti, F. Crosta, A. Vitali, M. Guerrieri, A. Frontini, B. Cannon, J. Nedergaard, S. Cinti, The presence of UCP1 demonstrates that metabolically active adipose tissue in the neck of adult humans truly represents brown adipose tissue, FASEB J. 23 (2009) 3113-3120.

[14] J. Nedergaard, B. Cannon, The changed metabolic world with human brown adipose tissue: therapeutic visions, Cell Metab. 11 (2010) 268-272.

[15] A. Cederberg, L.M. Gronning, B. Ahren, K. Tasken, P. Carlsson, S. Enerback, FOXC2 is a winged helix gene that counteracts obesity, hypertriglyceridemia, and diet-induced insulin resistance, Cell 106 (2001) 563-573.

[16] G. Leonardsson, J.H. Steel, M. Christian, V. Pocock, S. Milligan, J. Bell, P.W. So, G. Medina-Gomez, A. Vidal-Puig, R. White, M.G. Parker, Nuclear receptor corepressor RIP140 regulates fat accumulation, Proc. Natl. Acad. Sci. U. S. A. 101 (2004) 8437-8442.

[17] P. Seale, H.M. Conroe, J. Estall, S. Kajimura, A. Frontini, J. Ishibashi, P. Cohen, S. Cinti, B.M. Spiegelman, Prdm16 determines the thermogenic program of subcutaneous white adipose tissue in mice, J. Clin. Invest. 121 (2011) 96-105.

[18] P. Seale, B. Bjork, W. Yang, S. Kajimura, S. Chin, S. Kuang, A. Scimè, S. Devarakonda, H.M. Conroe, H. Erdjument-Bromage, P. Tempst, M.A. Rudnicki, D.R. Beier, B.M. Spiegelman, PRDM16 controls a brown fat/skeletal muscle switch, Nature 454 (2008) 961-967.

[19] B. Cousin, N. Bascands-Viguerie, N. Kassis, M. Nibbelink, L. Ambid, L. Casteilla, L. Penicaud, Cellular changes during cold acclimatation in adipose tissues, J. Cell. Physiol. 167 (1996) 285-289.

[20] M. Ghorbani, J. Himms-Hagen, Appearance of brown adipocytes in white adipose tissue during CL 316,243-induced reversal of obesity and diabetes in Zucker fa/fa rats, Int. J. Obes. Relat. Metab. Disord. 21 (1997) 465-475.

[21] J. Himms-Hagen, A. Melnyk, M.C. Zingaretti, E. Ceresi, G. Barbatelli, S. Cinti, Multilocular fat cells in WAT of CL-316243-treated rats derive directly from white adipocytes, Am. J. Physiol. Cell Physiol. 279 (2000) C670-C681.

[22] G. Barbatelli, I. Murano, L. Madsen, Q. Hao, M. Jimenez, K. Kristiansen, J.P. Giacobino, R. De Matteis, S. Cinti, The emergence of cold-induced brown adipocytes in mouse white fat depots is determined predominantly by white to brown adipocyte, Am. J. Physiol. Endocrinol. Metab. 298 (2010) E1244-E1253.

[23] N. Petrovic, T.B. Walden, I.G. Shabalina, J.A. Timmons, B. Cannon, J. Nedergaard, Chronic peroxisome proliferator-activated receptor gamma (PPARgamma) activation of epididymally derived white adipocyte cultures reveals a population of thermogenically competent, UCP1-containing adipocytes molecularly distinct from classic brown adipocytes, J. Biol. Chem. 285 (2009) 7153-7164.

[24] J. Ishibashi, P. Seale, Medicine. Beige can be slimming, Science 328 (2010) 1113-1114.

[25] J. Wu, P. Boström, L.M. Sparks, L. Ye, J.H. Choi, A.H. Giang, M. Khandekar, K.A. Virtanen, P. Nuutila, G. Schaart, K. Huang, H. Tu, W.D. van Marken Lichtenbelt, J. Hoeks,
S. Enerbäck, P. Schrauwen, B.M. Spiegelman, Beige adipocytes are a distinct type of thermogenic fat cell in mouse and human, Cell 150 (2012) 366-376.

[26] L.P. Kozak, R.A. Koza, R. Anunciado-Koza, T. Mendoza, S. Newman, Inherent plasticity of brown adipogenesis in white fat of mice allows for recovery from effects of post-natal malnutrition, PLoS One 7 (2012) e30392.

[27] A. Vitali, I. Murano, M.C. Zingaretti, A. Frontini, D. Ricquier, S. Cinti, The adipose organ of obesity-prone C57BL/6J mice is composed of mixed white and brown adipocytes, J. Lipid Res. 53 (2012) 619-629.

[28] Y.H. Lee, A.P. Petkova, E.P. Mottillo, J.G. Granneman, In vivo identification of bipotential adipocyte progenitors recruited by $\beta 3$-adrenoceptor activation and high-fat feeding, Cell Metab. 15 (2012) 480-491.

[29] T.B. Waldén, I.R. Hansen, J.A. Timmons, B. Cannon, J. Nedergaard, Recruited vs, non recruited molecular signatures of brown, "brite," and white adipose tissues, Am. J. Physiol. Endocrinol. Metab. 302 (2012) E19-E31.

[30] M.E. Lean, W.P. James, G. Jennings, P. Trayhurn, Brown adipose tissue in patients with phaeochromocytoma, Int. J. Obes. 10 (1986) 219-227.

[31] Q. Wang, M. Zhang, G. Ning, W. Gu, T. Su, M. Xu, B. Li, W. Wang, Brown adipose tissue in humans is activated by elevated plasma catecholamines levels and is inversely related to central obesity, PLoS One 6 (2011) e21006.

[32] I. Kuji, E. Imabayashi, A. Minagawa, H. Matsuda, T. Miyauchi, Brown adipose tissue demonstrating intense FDG uptake in a patient with mediastinal pheochromocytoma, Ann. Nucl. Med. 22 (2008) 231-235.

[33] L.Y. Yamaga, A.F. Thom, J. Wagner, R.H. Baroni, J.T. Hidal, M.G. Funari, The effect of catecholamines on the glucose uptake in brown adipose tissue demonstrated by (18)F-FDG PET/CT in a patient with adrenal pheochromocytoma, Eur. J. Nucl. Med. Mol. Imaging 35 (2008) 446-447.

[34] A.M. Cypess, C.R. Kahn, Brown fat as a therapy for obesity and diabetes, Curr Opin. Endocrinol. Diabetes Obes. 17 (2010) 143-149.

[35] S. Cinti, M. Cigolini, O. Bosello, P. Björntorp, A morphological study of the adipocyte precursor, J. Submicrosc. Cytol. 16 (1984) 243-251.

[36] K.V. Tran, O. Gealekman, A. Frontini, M.C. Zingaretti, M. Morroni, A. Giordano, A. Smorlesi, J. Perugini, R. De Matteis, A. Sbarbati, S. Corvera, S. Cinti, The vascular endothelium of the adipose tissue gives rise to both white and brown fat cells, Cell Metab. 15 (2012) 222-229.

[37] G.H. Vijgen, N.D. Bouvy, G.J. Teule, B. Brans, P. Schrauwen, W.D. van Marken Lichtenbelt, Brown adipose tissue in morbidly obese subjects, PLoS One 6 (2011) e17247.

[38] G.H. Vijgen, N.D. Bouvy, G.J. Teule, B. Brans, J. Hoeks, P. Schrauwen, W.D. van Marken Lichtenbelt, Increase in brown adipose tissue activity after weight loss in morbidly obese subjects, J. Clin. Endocrinol. Metab. 97 (2012) E1229-E1233.

[39] T. Yoneshiro, S. Aita, M. Matsushita, T. Kameya, K. Nakada, Y. Kawai, M. Saito, Brown adipose tissue, whole-body energy expenditure, and thermogenesis in healthy adult men, Obesity (Silver Spring) 19 (2011) 13-16.

[40] V. Ouellet, S.M. Labbé, D.P. Blondin, S. Phoenix, B. Guérin, F. Haman, E.E. Turcotte, D. Richard, A.C. Carpentier, Brown adipose tissue oxidative metabolism contributes to energy expenditure during acute cold exposure in humans, J. Clin. Invest. 122 (2012) 545-552.

[41] D.E. Cummings, E.P. Brandon, J.V. Planas, K. Motamed, R.L. Idzerda, G.S. McKnight Genetically lean mice result from targeted disruption of the RII beta subunit of protein kinase A, Nature 382 (1996) 622-626.

[42] K. Tsukiyama-Kohara, F. Poulin, M. Kohara, C.T. DeMaria, A. Cheng, Z. Wu, A.C Gingras, A. Katsume, M. Elchebly, B.M. Spiegelman, M.E. Harper, M.L. Tremblay, $\mathrm{N}$. Sonenberg, Adipose tissue reduction in mice lacking the translational inhibitor 4E-BP1, Nat. Med. 7 (2001) 1128-1132.

[43] A. Scime, G. Grenier, M.S. Huh, M.A. Gillespie, L. Bevilacqua, M.E. Harper, M.A Rudnicki, Rb and p107 regulate preadipocyte differentiation into white versus brown fat through repression of PGC-1alpha, Cell Metab. 2 (2005) 283-295.

[44] A. Vegiopoulos, K. Müller-Decker, D. Strzoda, I. Schmitt, E. Chichelnitskiy, A. Ostertag, M. Berriel Diaz, J. Rozman, M. Hrabe de Angelis, R.M. Nüsing, C.W Meyer, W. Wahli, M. Klingenspor, S. Herzig, Cyclooxygenase-2 controls energy homeostasis in mice by de novo recruitment of brown adipocytes, Science 328 (2010) 1158-1161.

[45] L. Madsen, L.M. Pedersen, H.H. Lillefosse, E. Fjaere, I. Bronstad, Q. Hao, R.K. Petersen, P. Hallenborg, T. Ma, R. De Matteis, P. Araujo, J. Mercader, M.L. Bonet, J.B. Hansen, B. Cannon, J. Nedergaard, J. Wang, S. Cinti, P. Voshol, S.O. Døskeland, K. Kristiansen, UCP1 induction during recruitment of brown adipocytes in white adipose tissue is dependent on cyclooxygenase activity, PLoS One 5 (2010) e11391.

[46] H. Yadav, C. Quijano, A.K. Kamaraju, O. Gavrilova, R. Malek, W. Chen, P. Zerfas, D Zhigang, E.C. Wright, C. Stuelten, P. Sun, S. Lonning, M. Skarulis, A.E. Sumner, T. Finkel, S.G. Rane, Protection from obesity and diabetes by blockade of TGF-beta/Smad3 signaling, Cell Metab. 14 (2011) 67-79.

[47] M. Christian, E. Kiskinis, D. Debevec, G. Leonardsson, R. White, M.G. Parker, RIP140 targeted repression of gene expression in adipocytes, Mol. Cell. Biol. 25 (2005) 9383-9391.

[48] J.G. Granneman, P. Li, Z. Zhu, Y. Lu, Metabolic and cellular plasticity in white adipose tissue I: effects of beta3-adrenergic receptor activation, Am. J. Physiol Endocrinol. Metab. 289 (2005) E608-E616.

[49] M. Jimenez, G. Barbatelli, R. Allevi, S. Cinti, J. Seydoux, J.P. Giacobino, P. Muzzin, F. Preitner, Beta 3-adrenoceptor knockout in C57BL/6J mice depresses the occurrence of brown adipocytes in white fat, Eur. J. Biochem. 270 (2003) 699-705.

[50] W. Cheng, Z. Zhu, X. Jin, L. Chen, H. Zhuang, F. Li, Intense FDG activity in the brown adipose tissue in omental and mesenteric regions in a patient with malignant pheochromocytoma, Clin. Nucl. Med. 37 (2012) 514-515.

[51] F.M. Fisher, S. Kleiner, N. Douris, E.C. Fox, R.J. Mepani, F. Verdeguer, J. Wu, A. Kharitonenkov, J.S. Flier, E. Maratos-Flier, B.M. Spiegelman, FGF21 regulates PGC-1alpha and browning of white adipose tissues in adaptive thermogenesis, Genes Dev. 26 (2012) 271-281. 
[52] R. De Matteis, J.R. Arch, M.L. Petroni, D. Ferrari, S. Cinti, M.J. Stock, Immunohistochemical identification of the beta(3)-adrenoceptor in intact human adipocytes and ventricular myocardium: effect of obesity and treatment with ephedrine and caffeine, Int. J. Obes. Relat. Metab. Disord. 26 (2002) 1442-1450.

[53] M. Cigolini, S. Cinti, O. Bosello, L. Brunetti, P. Björntorp, Isolation and ultrastructural features of brown adipocytes in culture, J. Anat. 145 (1986) 207-216.

[54] L.Z. Sharp, K. Shinoda, H. Ohno, D.W. Scheel, E. Tomoda, L. Ruiz, H. Hu, L. Wang, Z. Pavlova, V. Gilsanz, S. Kajimura, Human BAT Possesses molecular signatures that resemble beige/brite cells, PLoS One 7 (2012) e49452.

[55] J. Sanchez-Gurmaches, C.M. Hung, C.A. Sparks, Y. Tang, H. Li, D.A. Guertin, PTEN loss in the Myf5 lineage redistributes body fat and reveals subsets of white adipocytes that arise from Myf5 precursors, Cell Metab. 16 (2012) 348-362.

[56] S. Collins, K.W. Daniel, A.E. Petro, R.S. Surwit, Strain-specific response to beta 3-adrenergic receptor agonist treatment of diet-induced obesity in mice, Endocrinology 138 (1997) 405-413.

[57] C. Guerra, R.A. Koza, H. Yamashita, K. Walsh, L.P. Kozak, Emergence of brown adipocytes in white fat in mice is under genetic control. Effects on body weight and adiposity, J. Clin. Invest. 102 (1998) 412-420.

[58] A. Smorlesi, A. Frontini, A. Giordano, S. Cinti, The adipose organ: white-brown adipocyte plasticity and metabolic inflammation, Obes. Rev. 13 (2012) 83-96.

[59] L. Qiang, L. Wang, N. Kon, W. Zhao, S. Lee, Y. Zhang, M. Rosenbaum, Y. Zhao, W. Gu, S.R. Farmer, D. Accili, Brown remodeling of white adipose tissue by SirT1-dependent deacetylation of Ppary, Cell 150 (2012) 620-632.
[60] R. De Matteis, F. Lucertini, M. Guescini, E. Polidori, S. Zeppa, V. Stocchi, S. Cinti, R. Cuppini, Exercise as a new physiological stimulus for brown adipose tissue activity, Nutr. Metab. Cardiovasc. Dis. 26 (2012) 1442-1450.

[61] L. Cao, E.Y. Choi, X. Liu, A. Martin, C. Wang, X. Xu, M.J. During, White to brown fat phenotypic switch induced by genetic and environmental activation of a hypothalamic-adipocyte axis, Cell Metab. 14 (2011) 324-338.

[62] P. Boström, J. Wu, M.P. Jedrychowski, A. Korde, L. Ye, J.C. Lo, K.A. Rasbach, E.A. Boström, J.H. Choi, J.Z. Long, S. Kajimura, M.C. Zingaretti, B.F. Vind, H. Tu, S. Cinti, K. Højlund, S.P. Gygi, B.M. Spiegelman, A PGC1-alpha-dependent myokine that drives brown-fat-like development of white fat and thermogenesis, Nature 481 (2012) 463-468.

[63] M. Bordicchia, D. Liu, E.Z. Amri, G. Ailhaud, P. Dessì-Fulgheri, C. Zhang, N. Takahashi, R. Sarzani, S. Collins, Cardiac natriuretic peptides act via p38 MAPK to induce the brown fat thermogenic program in mouse and human adipocytes, J. Clin. Invest. 122 (2012) 1022-1036.

[64] A.J. Whittle, S. Carobbio, L. Martins, M. Slawik, E. Hondares, M.J. Vázquez, D. Morgan, R.I. Csikasz, R. Gallego, S. Rodriguez-Cuenca, M. Dale, S. Virtue, F. Villarroya, B. Cannon, K. Rahmouni, M. López, A. Vidal-Puig, BMP8B increases brown adipose tissue thermogenesis through both central and peripheral actions, Cell 149 (2012) 871-885.

[65] E. Hondares, R. Iglesias, A. Giralt, F.J. Gonzalez, M. Giralt, T. Mampel, F. Villarroya, Thermogenic activation induces FGF21 expression and release in brown adipose tissue, J. Biol. Chem. 15 (2011) 12983-12990. 